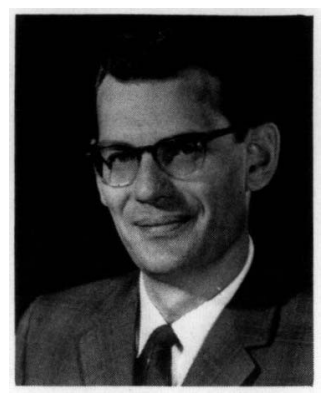

\title{
Automobile Accidents
}

\section{The Schools and Safety Education}

Donald F. Huelke

\begin{abstract}
$\prod_{\text {He }}$ HE leading killer of school children is traffic accidents. In our automobile-oriented society, safety education is critical. But what are the schools really doing in this area?

I feel that we have just begun to teach traffic safety, that it is in an embryonic stage in our school programs. We first begin driver education when students are 16, if we offer any auto safety program at all; yet we teach mathematics to children in the first grade. Since the leading cause of death between the ages of one and 41 is the motor vehicle accident, wouldn't it be logical to institute a program of traffic safety in our school system?

Children are receptive; they can be taught why they need to wear a seat belt, why they should not bother Daddy when he's driving, how a seat belt should be worn, and that the doors should be locked from the inside to prevent door openings. This doesn't need to be as concerted an effort in the school system as is instruction in reading, writing, and arithmetic. However, if appropriate information is included in the curriculum at each grade level,
\end{abstract}

Donald F. Huelke is associate professor of anatomy at the University of Michigan Medical School and a member of the executive committee of the university's Highway Safety Research Institute. He accompanied this address with a showing of slides of crashes he has investigated. 
traffic safety will be well ingrained in the 16-year-old who is ready to learn to drive.

Safety education can be integrated into courses in science or social studies. For example, the immense forces involved in crashes aren't generally appreciated-but would make interesting material for science students at several grade levels.

A major contribution of safety education would be to show the value of wearing safety belts. My six-year research program on auto fatalities has revealed that some 40 percent of those killed in crashes would have lived if they had worn seat belts.

\section{Number One Killer}

Ejection is the leading cause of death in automobile accidents. Many envision ejection as occurring by failure of the door-latch mechanism alone, but other aspects are just as important. For example, Gross at the Institute of Transportation and Traffic Engineering, U.C.L.A., has shown that doors can be opened by latch failure caused by the impact of another car directly against the door or to the car body adjacent to the latch mechanism, by a seat ramming the opposite door, bending of the vehicle in a horizontal plane, and contact by the outside handle push button with the ground in rollover accidents, as well as by numerous other mechanisms.

It has also been shown that a seat or occupant striking the door can generate upwards of 2,000 pounds of force, which can cause the door to open. Likewise, bending of the latch remote rod from direct door impact can open the door.

To keep doors closed and prevent occupant ejection, the latch mechanism must, of course, be as strong as required, but it is equally important that the occupants and the seats, which can strike the door from within, be more adequately secured. The integral strength of the door latch and striker in American cars has been increased in recent years. Instead of door-latch striker separation, more and more cases have been seen where the latch striker interlock is stronger than the attachments of these components to the door or pillar and either the latch or the striker is ripped from its mountings under severe loading conditions.

Especially in rollover accidents, doors can be opened by the outer door push button striking the road surface or the gravel off the road. This can be prevented only by locking the doors 
from the inside-an overt, purposeful act on the part of the occupants.

The controversy over laminated versus tempered windshields and whether these should or should not pop out is entirely unnecessary when all agree that the occupants should be wearing seat belts or, better yet, upper-torso restraints with seat belts.

\section{Seat Belts}

Of the 48 occupants who were killed by ejection, probably 38 , or 80 percent, could have survived had they only worn seat belts. If single shoulder belts had been worn along with seat belts, three others (two percent) probably would have been saved. Thus, the function of seat belts, to keep the occupants within the car, can readily be seen.

Furthermore, we must educate the public to lock the car doors, thereby preventing accidental door openings. When one purposely combines the use of a seat belt with locking the door he is thinking about safety, and this may in turn reflect on his driving behavior.

Additionally, I feel, it is imperative that we educate the parents of small children as to the use of child restraint systems. We have seen children catapult forward from the rear seat into the instrument panel. I have examples of cases in which infants, riding in baby seats attached to the back of the front seat were catapulted forward into the instrument panel, receiving serious injuries. On the other hand, I have several cases in which small children were wearing adult seat belts and received only minor injuries, mainly belt bruises and a bump on the head.

I am convinced that no single panacea will be found to reduce traffic mortality and injury. The need for safety features and design in the automobile is obvious, but also needed is a concentrated effort to educate the occupants to use seat belts, serious effort for safer highway and off-roadway designs, and adequate legislation to help prevent the first collision.

The responsibility is yours. Only you can ensure that in the school's educational programs safety receives the emphasis demanded by the value you place on your students' lives. 